\title{
Hybrid Membranes Based on Clay-Polymer for Removing Methylene Blue from Water
}

\author{
Ahmed M. Khalil ${ }^{1, *}$ and Sayed H. Kenawy ${ }^{2}$ \\ ${ }^{1}$ Photochemistry Department, National Research Centre, El-Buhouth St., Dokki - 12622, Giza, Egypt \\ ${ }^{2}$ Refractories, Ceramics and Building Materials Department, National Research Centre, El-Buhouth St., \\ Dokki-12622, Giza, Egypt \\ * Corresponding author: E-mail: akhalil75@yahoo.com \\ Phone: +20233371635 Fax: +20233370931
}

Received: 04-28-2019

\begin{abstract}
Water pollution is a serious environmental problem. Methylene blue is among the dyes that may exist in waste water. Adsorption is an effective process to remove dyes from contaminated water. Hybrid membranes based on clay-polymer; namely kaolin and polystyrene were prepared to absorb the present methylene blue in aqueous solution. These membranes were fired at $1000^{\circ} \mathrm{C}$ to degrade polystyrene leaving cavities in the clay matrix with an expanded surface area and porous structure. The membranes were characterized via X-ray diffraction and Infrared spectroscopy. The morphological structure was investigated by using scanning electron microscopy. In this work, we are focusing on facile means represented in UV-Vis spectroscopy, to monitor the adsorption efficiency of the prepared membranes. From the results, the membrane loaded with $20 \%$ polystyrene by weight showed the optimum performance in adsorbing methylene blue from water.
\end{abstract}

Keywords: Clay; polystyrene; membrane; dye removal; methylene blue

\section{Introduction}

The demand to obtain fresh water increases rapidly with the progressive population growth. The scarcity of potable water is due to environmental degradation resulting from industrial development and its contaminants. To save human health and the environment, water purification is essential to remove turbidity, offensive smell and taste. $\mathrm{Pu}$ rifying water can be achieved by using various methods including coagulation, flocculation, ozonation, reverse osmosis, and adsorption. ${ }^{1-4}$ The kind of pollutant contributes in determining the method of removing it. Chemicals are among the major water contaminants. These chemicals participate in various industries like pharmaceutics, printing and textiles. Organic compounds are the major pollutants present in the aforementioned industries; mainly in synthetic dyes. Different azodyes are used in textile industries. However, most of these dyes are highly carcinogenic even if they are present in minute quantities. Methylene blue (MB) as a cationic dye is commonly used for coloring, in addition to microbiology, surgery, diagnostics. ${ }^{5-7}$ Though MB is not strongly hazardous, it may have some harmful effects. Acute exposure to $\mathrm{MB}$ leads to an increase in heart rate, shock, cyanosis, jaundice, and tissue necrosis in humans. ${ }^{8,9} \mathrm{MB}$ may act as an eye irritant to humans and animals. Hence, the treatment of effluents loaded with MB is interesting to avoid the harmful impacts on the carrying waters. ${ }^{10,11}$ Recently, there is an increasing interest to investigate porous ceramic composite materials. Many products are made of porous ceramic, such as membranes, catalytic substrates and filters. This is due to their notable features such as high temperature stability, high permeability, excellent catalytic activity and low bulk density.

Clays and organic polymers are among the materials that can be employed individually or after mixing to form composites that can be used in adsorption, heavy metal removal, and paper fillings. ${ }^{12-14}$ Clay minerals contribute in various domains such as in preparing polymers nanocomposites and ceramics. The abundance of natural clay minerals of low cost is likely to make them a strong candidate as an adsorbent for the removal of toxic materials from wastewater and other environments. These minerals consist of tetrahedral and octahedral layers. Hence, they are characterized by the ratio of this sheets/layers in the 
structure. The clay consisting of 2 tetrahedral sheets and 1 octahedral sheet is known as a 2:1 clay type (3 sheets). Meanwhile, those clays which comprise 1 octahedral sheet and 1 tetrahedral sheet are called 1:1 (2 sheets) clay types. ${ }^{15-17}$ These minerals have an important role in trapping contaminants from water in soil. The commonly used clays include montmorillonite, smectite, kaolinite and illite. They are present in almost all sedimentary rocks. Large ratio of surface area to volume or fine particles gives clay minerals a set of unique adsorption properties for various organic dyes, metals or other environmental pollutants. ${ }^{18-20}$ Furthermore, adsorption using inexpensive and affordable adsorbent would make removal of different dyes or metal pollutants from wastewater feasible. The abundance of natural clay minerals in a low cost permits them to become a strong candidate as an adsorbent for getting rid of toxins from wastewater. Clay-organic interaction is widely investigated. Association of an organic molecule with a clay particle may take place. The organic molecules may be adsorbed onto the clay minerals by ion-dipole forces or it may complex with a counter ion of the clay mineral or it may undergo a cation or anion exchange with original counter ions. Ceramic is produced by firing a mixture of materials for inorganic and non-metallic oxide; nitride or carbide materials. Many types of additives can be used with the ceramic matrix before or after combustion for enhancing its properties. Ceramic membranes are made from clay and waste materials. They are favored as low cost materials. These substrates attract attention for being employed in water treatment applications. Among these membranes, hydrophobic clay-alumina-based capillary membrane was used in desalination application. ${ }^{20}$ It was prepared from a green silica-based ceramic hollow fiber membrane from waste rice husk. Upon comparing ceramic membranes to polymeric ones, it was found the latter may face some drawbacks. Sometimes, they are unable to proceed in their required processes at high temperature or severe chemical circumstances. Hence, ceramic membranes possess merits over polymeric membranes. This can be correlated to their non-swelling behavior and thermal stability. ${ }^{17,18}$

Used polystyrene exists as a solid municipal waste through the consumed scrap. Expanded polystyrene (EPS) is substrate which is utilized in large amounts in packaging applications or as an insulator. EPS is a tough, foamy material. It is among the major plastic wastes. It possess a low density, chemical and thermal resistances with a low cost. $^{21,22}$ The augmenting amount of consumed EPS is attracting attention to be recycled. ${ }^{23}$ The pellet of EPS is nearly spherical. It consists of approximately $2 \%$ polystyrene and the rest percentage is air. ${ }^{24}$ EPS is hydrophobic. Thereafter, it can be used as a light aggregate for reaching a light weight foam concrete. ${ }^{25,26}$ It can be used producing a walling substrate in construction. Among the disadvantages of EPS is being a non-biodegradable substrate. ${ }^{27}$ Therefore, inserting it in a wall panel matrix will be beneficial to dispose consumed EPS.
The aim of this work is to prepare hybrid porous membranes based on kaolin and polystyrene to adsorb methylene blue from water. The membranes will possess pores resulting from firing the prepared membranes with degrading the expanded polystyrene. The adsorption changes are proposed to be followed up in an easy and rapid process which is UV-Vis spectral analysis for the resulting solutions after MB adsorption. Kinetics and related isotherms for determining the adsorption capacitates are not disused in the current work.

\section{Experimental}

\section{1. Materials and Instruments}

The used raw materials in this study are kaolin and expanded polystyrene. Kaolin was provided from Kalabsha - Egypt. Expanded polystyrene (EPS) pellets with an average diameter $2 \mathrm{~mm}$ were obtained by shredding post-consumed polystyrene foam. The polymeric beads were washed with water and dried. Expanded polystyrene has a role in providing cavities in the ceramic matrix as EPS degrades at high temperatures. Methylene blue (MB) powder was purchased from Sigma Aldrich. MB powder was used to prepare an aqueous solution with $250 \mathrm{mg} / \mathrm{l}$ concentration at $25^{\circ} \mathrm{C}$. This solution is utilized in carrying out the adsorption investigations. The chemical constituents of the clay were investigated using X-rays Fluorescence equipped by a modern wavelength dispersive spectrometer (Axios PANalytical 2005, Netherlands).

The densification parameters in terms of bulk density (BD), apparent porosity (A. P.), closed - porosity (CP) and total porosity were determined according to the ASTM : C 20-46. This method is based on boiling the sample in water for $2 \mathrm{~h}$. The saturated sample were weighed in air and immersed in water. The weight of each dry sample was obtained after drying the saturated samples overnight at $110^{\circ} \mathrm{C}$. The bulk density as well as apparent porosity were calculated using the following equations:

Bulk density $(\mathrm{BD})=\mathrm{Wd} / \mathrm{Ws}-\mathrm{Wi} \quad\left(\mathrm{g} \mathrm{cm}^{-3}\right)$

Apparent porosity (A. P. $)=(\mathrm{Ws}-\mathrm{Wd} / \mathrm{Ws}-\mathrm{Wi}) \mathrm{X}$ $100(\%)$

where: $\mathrm{Wd}=$ weight of the dry sample

Ws = weight of the saturated sample

$\mathrm{Wi}=$ weight of the saturated sample immersed in water

The fired samples were characterized using the scanning electron microscopy (SEM) for microstructure investigations with energy-dispersive spectroscopy (EDX; JEOL JXA-840 A, Electron probe micro-analyzer, Japan). Infrared spectra of the obtained membranes were attained using Fourier transformer infrared spectrophotometer (FTIR) (model FT/IR-6100 Type A, Germany) before and after adsorption process. X-Ray Diffraction (XRD) patterns were also carried out for the obtained membrane before and after adsorption using (XRD, BRUKER, D8 ADVANCE $\mathrm{CuO}$ target, Germany), based generator X-ray dif- 
fractometer using $\mathrm{CuK}_{\alpha}$ radiation. The working conditions of the diffractogram was recorded in a $2 \theta$ range from $5-70^{\circ}$. UV-Visible spectra were performed by using Agilent Cary 100 UV/VIS spectrophotometer.

\section{2. Methods}

\section{2. 1. Steps of Preparing the Membrane}

1) Batching: It is the process of weighing the clay according to the recipes and preparing them for mixing, weighing different powdered raw materials in different percentages to form the batch composition for different membranes. 2) Milling: It is the process by which the size of the clay turns from large particles to smaller ones. It is generally performed mechanically, including attrition. Milling may involve breaking up cemented material (individual particles retain their shape) or pulverization (grinding the particles themselves to a smaller size). 3) Sieving: It is a process by which un-milled materials are separated from fine powdered forms. 4) Mixing: This step takes place after batching and is performed with ribbon mixer. Kaolin powder was mixed with different percentages of expanded polystyrene (EPS). The amount of expanded polystyrene varied in the five samples in the range of $(0,2.5,5,10$ \& $20 \%$ ) with respect to kaolin weight. The symbols referring to the prepared membranes are displayed in Table 1. 5) Membrane preparation: The main components used in producing the ceramic membranes are clay powder, or-

Table 1. Composition of the starting materials for preparing the porous ceramic membranes.

\begin{tabular}{ccc}
\hline Sample & $\begin{array}{c}\text { Kaolin } \\
\text { (wt. \%) }\end{array}$ & $\begin{array}{c}\text { Expanded } \\
\text { Polystyrene (wt. \%) }\end{array}$ \\
\hline Blank & 100 & 0.0 \\
A & 97.5 & 2.5 \\
B & 95 & 5 \\
C & 90 & 10 \\
D & 80 & 20 \\
\hline
\end{tabular}

ganic polymer and water as solvent. Upon selecting the inorganic powder, important factors have to be considered. They are particle size and distribution, as well as the shape of the particles. They affect the porosity, pore size and pore size distribution of the final product. The five membranes were fabricated by means of using extruder. The membranes were prepared as cylinders with $10 \mathrm{~mm}$ diameter and $30 \mathrm{~mm}$ height.

Kaolin and expanded polystyrene were mixed properly to ensure homogenous distribution in the whole samples. Water was then added in a fixed amount to the samples. The produced membranes were dried at $110^{\circ} \mathrm{C}$ to be ready for adsorption experiments. Figure 1 shows a scheme for the preparation steps of the membranes and evaluating them in adsorbing $\mathrm{MB}$ from water.

\section{Results and Discussion}

\section{1. Chemical Composition of Kaolin}

From the chemical composition of kaolin material; alumina and silica are found to be the major constituents with other minor ones, while the percentage of manganese (II) oxide ${ }^{28}$ could not be determined. The loss on ignition (LOI) corresponds to water vapor from hydroxide reaction in the kaolin minerals. Moreover, the burning out of organic matter beside the carbonate decomposition in $\mathrm{CO}_{2}$ and oxide of the minerals is shown in Table 2 .

\section{2. Effect of Polystyrene Content}

Expanded polystyrene (EPS) acts as the pore maker in the prepared membranes and affects the physical properties of kaolin which was fired up to $1000^{\circ} \mathrm{C}$. The permeability of these membranes was originated from the burning of the introduced polymer upon preparation. This process forms various kinds of closed cavities like pores with flaky structure. The influence of EPS content is shown in Figure 2. The prepared samples contain various polysty-

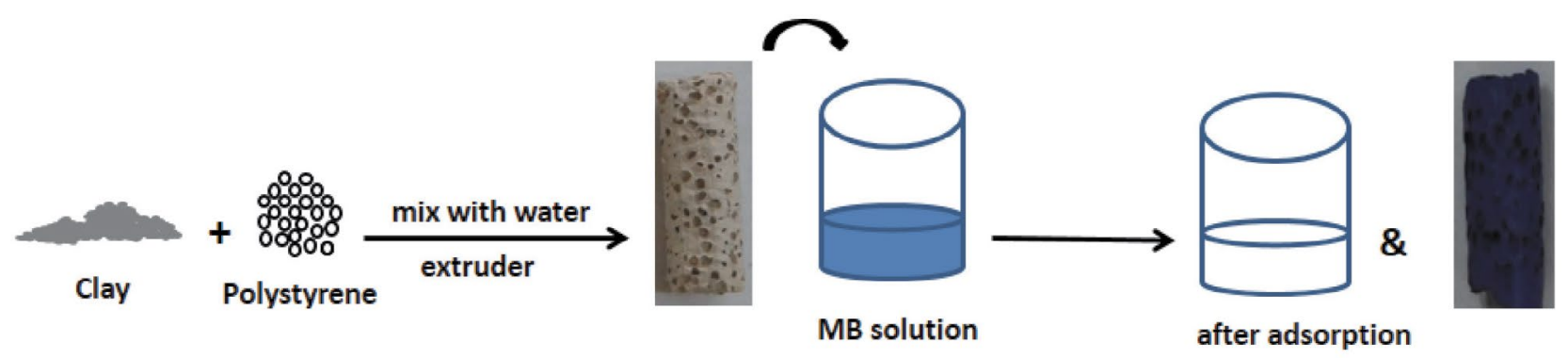

Figure 1. Schematic illustration for the ceramic membrane preparation and using it in adsorbing methylene blue.

Table 2. Chemical composition of Kaolin.

\begin{tabular}{lccccccccccc}
\hline Kaolin components & $\mathrm{SiO}_{2}$ & $\mathrm{Al}_{2} \mathrm{O}_{3}$ & $\mathrm{TiO}_{2}$ & $\mathrm{Fe}_{2} \mathrm{O}_{3}$ & $\mathrm{SO}_{3}$ & $\mathrm{MgO}$ & $\mathrm{CaO}$ & $\mathrm{P}_{2} \mathrm{O}_{5}$ & $\mathrm{~K}_{2} \mathrm{O}$ & $\mathrm{Na}_{2} \mathrm{O}$ & $\mathrm{LOI}$ \\
Composition \% & 44.56 & 37.34 & 1.98 & 1.12 & 0.02 & 0.39 & 0.09 & 0.08 & 0.02 & 0.1 & 14.3 \\
\hline
\end{tabular}



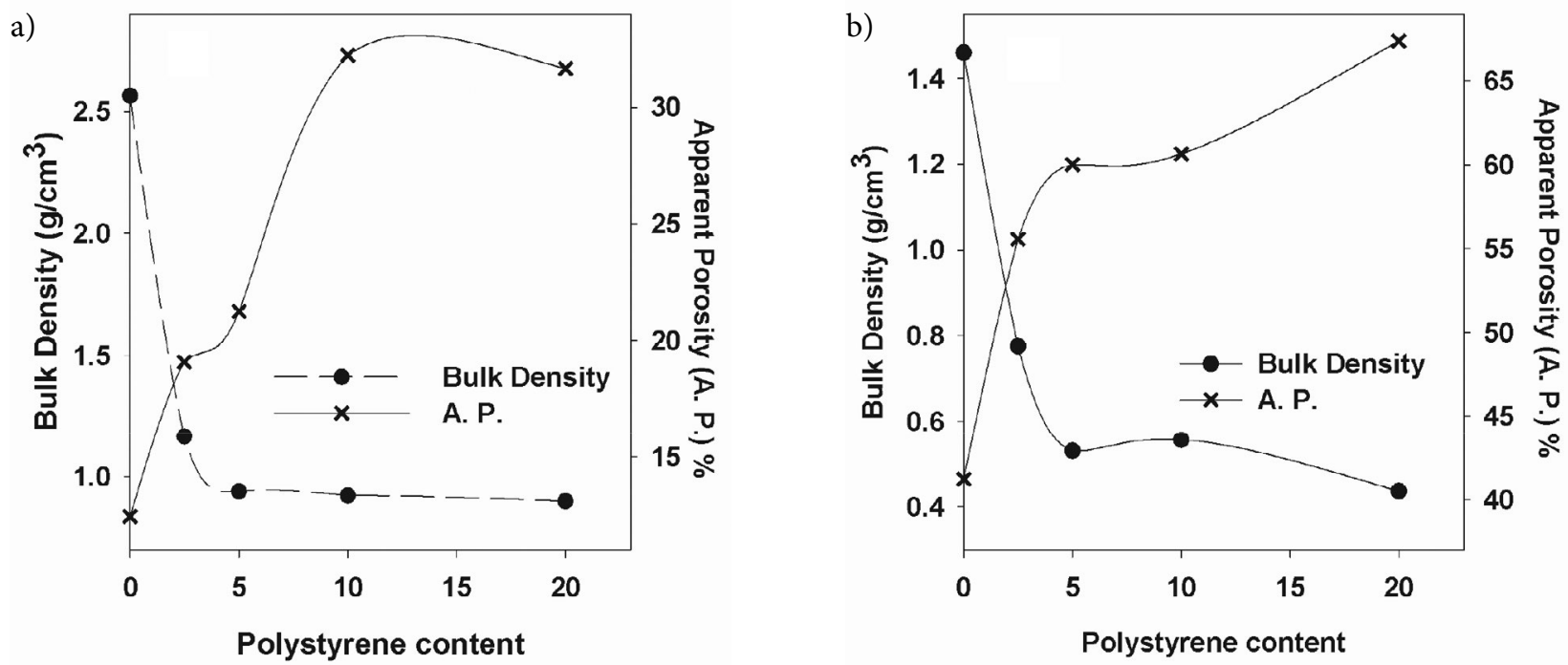

Figure 2. Bulk density and apparent porosity of the prepared membranes (a) before and (b) after MB adsorption.

rene ratios from 0 to $20 \%$ by weight. Known percentages of water were added to each of these mixes. The apparent porosity (A. P.) of the ceramic membranes increases proportionally as the polystyrene content in the burnt samples increases. The porosity may be correlated to the formed closed pores during firing the embedded polystyrene inside the clay matrix to produce voids. Meanwhile, the presences of this porosity reduces the bulk density of samples. Sample (D) with $20 \%$ polystyrene shows the optimum percentage for adding this polymer. At higher contents of polystyrene, the ceramic membrane tends to be fragile and inconsistent. After adsorption, sample (D) is more likely to assist in increasing pore volume with decreasing the bulk density. This behavior may be changed due to penetration of the methylene blue dye in closed pores via osmotic pressure through capillary nanopores.

\section{3. UV-Vis Spectral Analysis}

UV-Vis spectroscopy measurements were used to monitor the impact of ceramic membrane in adsorbing methylene blue and removing it from water. The ceramic
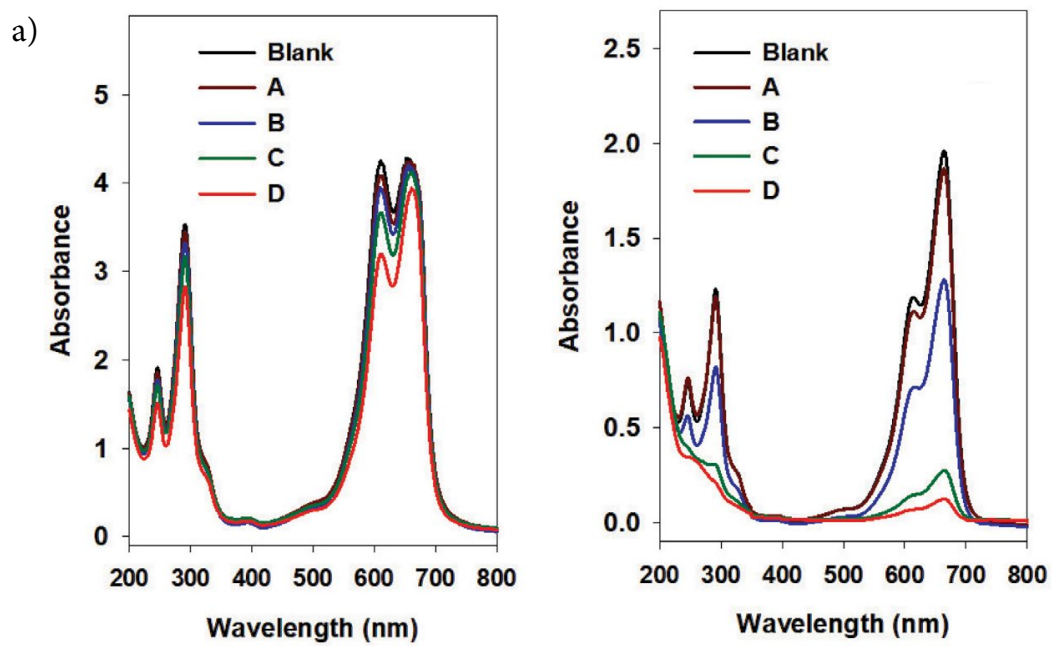

b)

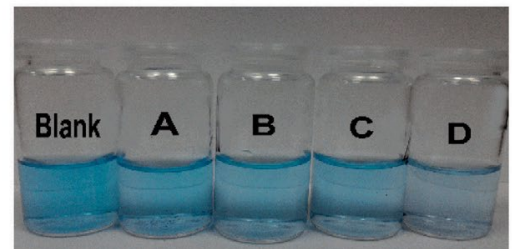

Figure 3. UV-Vis absorption spectra with photos for the collected eluents form the different membranes immersed in MB aqueous solutions resulting from adsorption reactions: a) after $60 \mathrm{~min}$. and b) after 24 hours. An inset photograph for the eluents after 24 hours. 
membranes with different pore contents resulting after firing and losing polystyrene; were soaked in aqueous solutions of methylene blue at $25^{\circ} \mathrm{C}$. UV-Vis spectra were recorded at different time intervals from starting the adsorption process. The first obvious change was enrolled after 60 minutes. In Figure 3a, the characteristic peaks of methylene blue appear at 607 and $660 \mathrm{~nm}$. The intensity of the peaks decrease proportionally with increasing the pores amount in the ceramic membranes. This denotes to the increased surface. Upon elapsing the time, it is noticed that the UV-Vis peaks of MB decrease as shown in Figure $3 \mathrm{~b}$. After 24 hours, the samples were analyzed to see the changes with gradual fading in the blue color. The results illustrate that the characteristic peaks of $\mathrm{MB}$ decreased drastically. The collected eluents from the samples from the tested MB solutions are represented in an inset photograph in Figure 3. They show a gradual decrease in the blue tint of MB. For the membrane sample (D) with $20 \%$ EPS, the membrane adsorbed $\mathrm{MB}$, with almost clear sample of water. This points to the efficiency of the prepared ceramic membrane to remove methylene blue from water after 24 hours at $25{ }^{\circ} \mathrm{C}$. No more samples were analyzed at extra time intervals attempting to detect the estimated time for dye adsorption at certain pore content in the membrane; i.e. to avoid passing or losing the end point as in titration experiments.

\section{4. Morphological Analysis and Spectral Changes Before and after MB Adsorption}

SEM micrographs of the ceramic structure, before and after MB adsorption are shown in Figure 4 displaying the cross-sections of ceramic samples fired at $1000{ }^{\circ} \mathrm{C}$. They elucidate an asymmetric morphology, with different size granules of approximately $1 \mu \mathrm{m}$ (alumina, and silica) and smaller particles (clay) bounded with each other forming the primary vitrified skeletal structure of the alumina-silica with holes, pores or cavity like pores. This kind of ceramic granules have many grooves as well as closed pores on the surface extending to the core of the ceramic matrix. ${ }^{14,16}$ Macro-voids in Figures ( $4 \mathrm{a}$ and $\mathrm{b}$ ) can be seen. These pores have an extended irregular form. The measure of pores in the ceramic samples are in the range of 1-1.7 $\mathrm{mm}$. Rough surface for the membrane can be noticed before adsorption. After adsorbing methylene blue, the surface became smoother due to the accumulation of methylene blue on the ceramic top with covering some closed pores. The micrographs of Figures $(4 \mathrm{c}$ and $\mathrm{d}$ ) represent higher magnification for the corresponding Figure (4 a and $b$ ) respectively. They reveal the heterogeneous nature of surface morphology of the fired kaolin sample. They clarify that crystals possess a foliation like morphology for kaolinite. The typical laminated and layered structure in
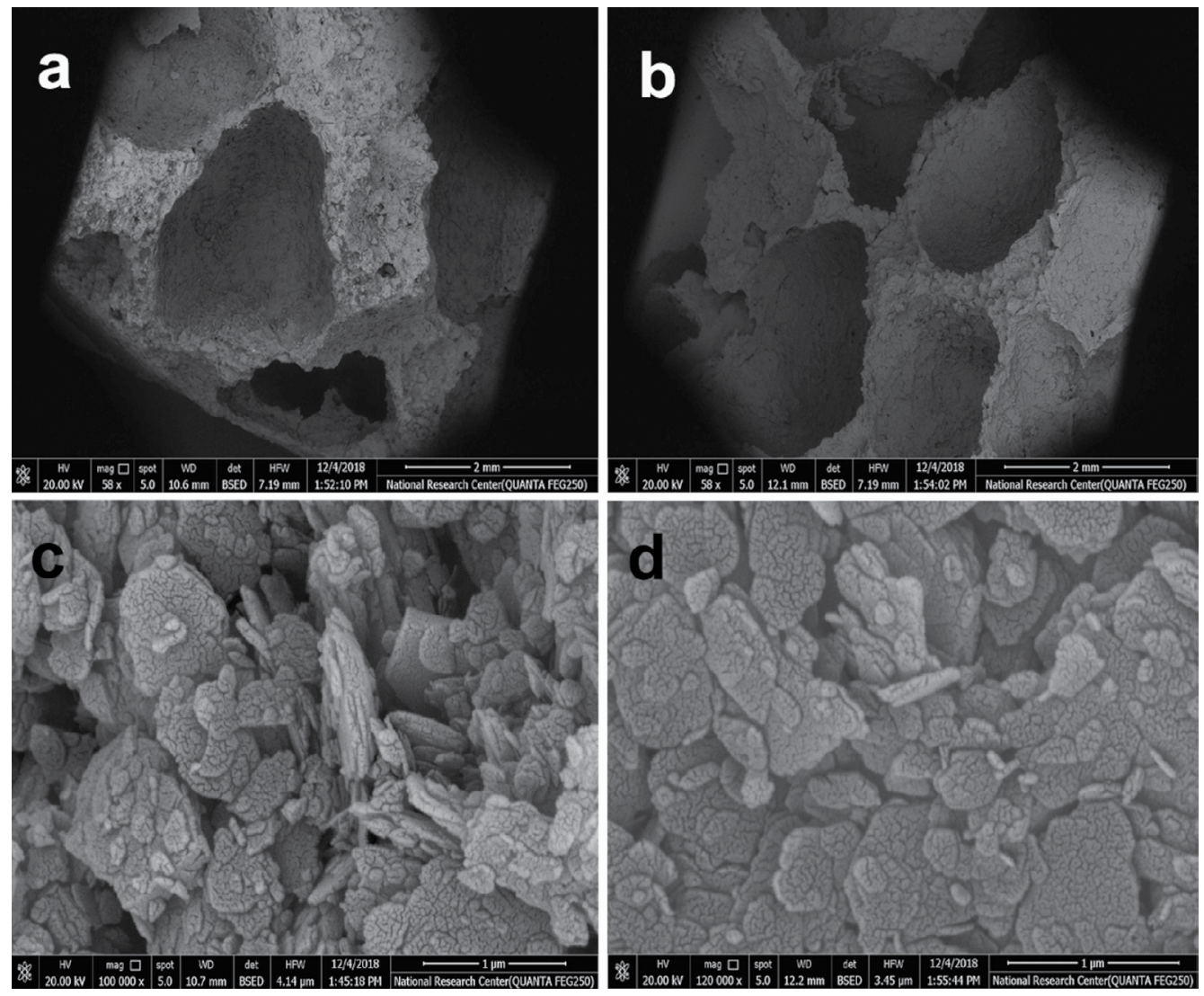

Figure 4. SEM of the ceramic membrane before and after MB adsorption. 


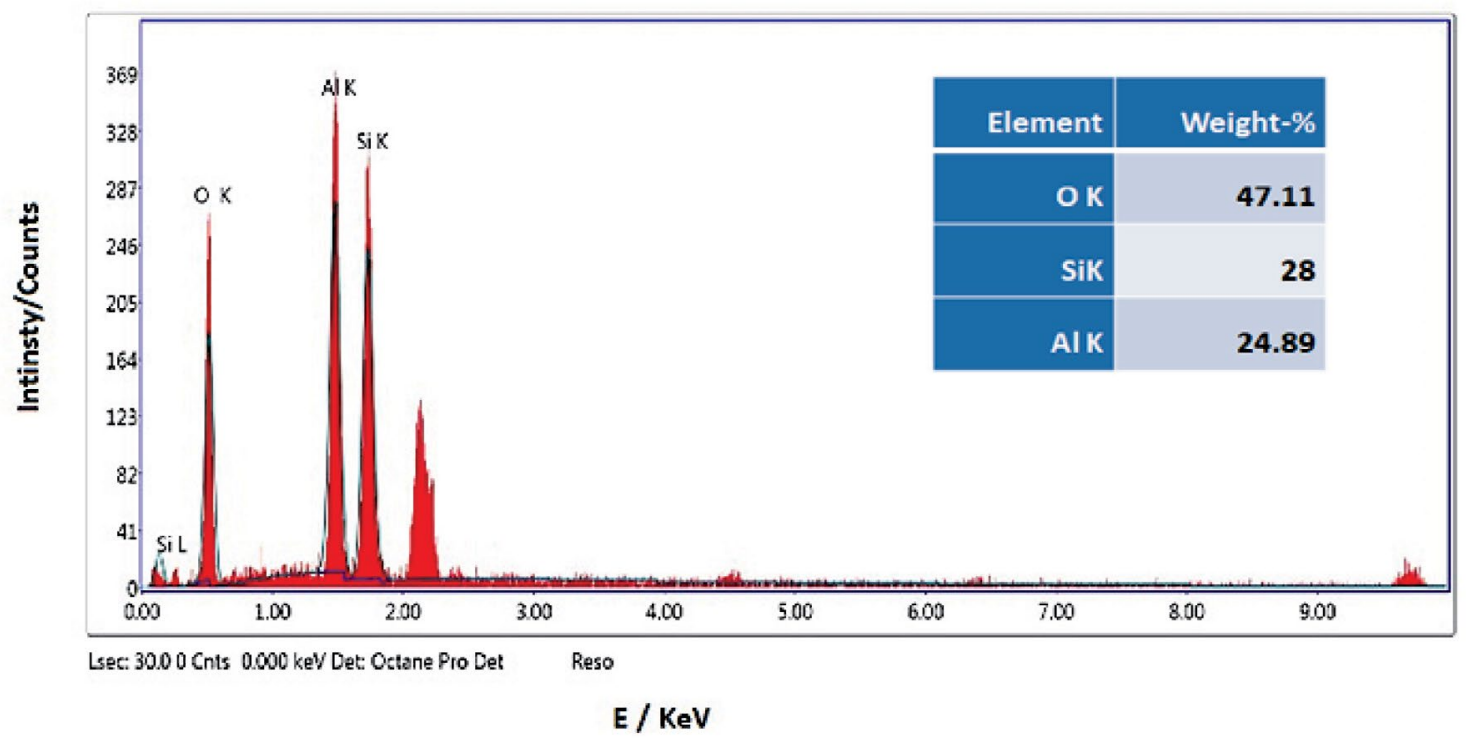

Figure 5. The EDX Microanalysis of mullite sample fired at $1000^{\circ} \mathrm{C}$.

the granules amplified the specific surface area of the ceramic membrane and favored pollutants adsorption into the inner positions of the ceramic body. The augmenting number of pores allows higher adsorption capacity for the dye onto the ceramic surface. The SEM analysis of the MB coated ceramics and uncoated confirmed the results of porosity and density. It can be noticed that expanded polystyrene content $20 \%$ in the membrane decreased the bulk density and increased the apparent porosity for sample (D) before and after MB adsorbing MB.

Figure 5 shows the EDX analysis of the ceramic matrix with mullite phase resulting from firing kaolin at $1000{ }^{\circ} \mathrm{C}$. It confirms that mullite does not contain any foreign inclusions. ${ }^{29}$ The tested sample shows the $\mathrm{Al} / \mathrm{Si}$ ratio to be $\approx$ 0.84 as shown in Table 2. It is less than the stoichiometric composition of mullite (Al/Si 3:1). ${ }^{30}$ However, the surplus silica content may exist as glass. The $\mathrm{Al} / \mathrm{Si}$ weight ratio confirmed the ratio of the starting materials which was previously determined.

FTIR spectra of the fired samples before and after immersion in methylene blue are plotted in Figure 6. The main characteristic bands of the kaolinite are highlighted as follow, the bands at 3770 to $3714 \mathrm{~cm}^{-1}$ which represent the $\mathrm{H}-\mathrm{O}-\mathrm{H}$ stretching free hydroxyl. This result was confirmed by previous work ${ }^{31}$ where the bands at 3694 and $3619 \mathrm{~cm}^{-1}$ show (OH stretching vibrations). The membrane sample (before adsorption) shows a broad but weak absorption band in the range $3419-3471 \mathrm{~cm}^{-1}$. The band at $3419 \mathrm{~cm}^{-1}$ along with weak band around 1619 and 1637 $\mathrm{cm}^{-1}$ are attributed to the stretching vibrations of the free hydroxyl group these may due to moisture accompanied with the sample. ${ }^{19}$ FTIR spectra of the two samples show characteristic bands pointing to the formation of metakaolin. A sharp band at $1101 \mathrm{~cm}^{-1}$ is attributed to overlap of the double bond at $883 \mathrm{~cm}^{-1}$ and $840 \mathrm{~cm}^{-1}$ that characterizes $\mathrm{Al}-\mathrm{O}$ and $\mathrm{O}-\mathrm{Al}-\mathrm{O}$ stretching vibration or correspond-

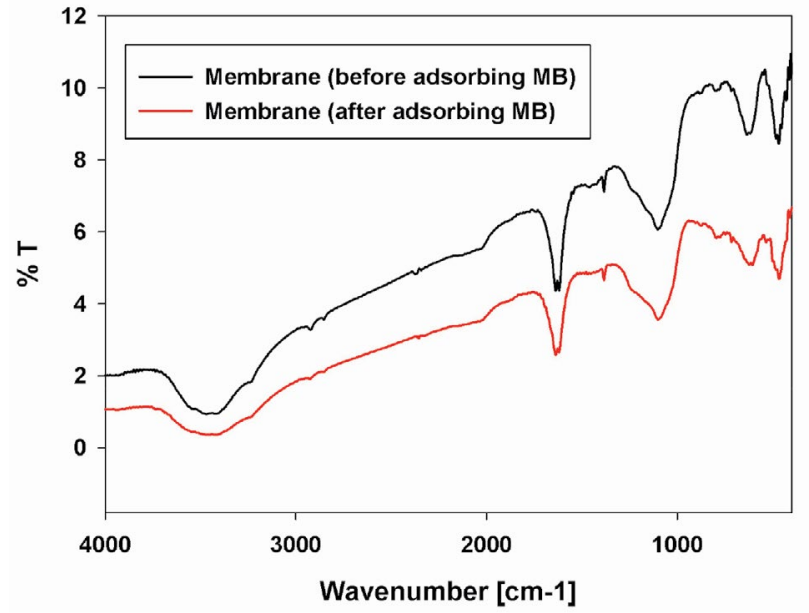

Figure 6. FTIR of a) fired kaolin at $1000^{\circ} \mathrm{C}$ before adsorption and b) covered with methylene blue after adsorption.

ing to $\mathrm{Si}-\mathrm{O}-\mathrm{Al}$ bonds. A sharp band with lower intensity is observed at $\sim 412 \mathrm{~cm}^{-1}$ that characterizes Si-O bond. Moreover, sharp bands at $\sim 582 \mathrm{~cm}^{-1}, 794,781$ and 643 $\mathrm{cm}^{-1}$ point to Al-O tetrahedral and Al-O octahedral bonds respectively. ${ }^{32}$

The XRD patterns for the membranes before and after $\mathrm{MB}$ adsorption are shown in Figure 7 . The main peaks for the clay appear at $2 \theta=20.89^{\circ}$ and $26.65^{\circ}$ as displayed in Figure $7 \mathrm{a}$. They are characteristic bands for quartz $\mathrm{SiO}_{2}$ which is a silica polymorph. It consists of interconnected $\mathrm{SiO}_{2}$ tetrahedral that build up a rigid three-dimensional network. Two peaks appear at $2 \theta=27.5$ and $60.04^{\circ}$. They may refer to kaolinite clay mineral (Microcline $\mathrm{KAlSi}_{3} \mathrm{O}_{8}$ ). The patterns in Figure $7 \mathrm{~b}$ for the sample loaded with $\mathrm{MB}$ showed slight increase in the intensities at $2 \theta=20.6,25.8$. However, a new peak appears at $2 \theta=37.22$. It can be referred to the adsorption of $\mathrm{MB}$ onto the clay particles. It was concluded that during the adsorption process of $\mathrm{MB}$ 


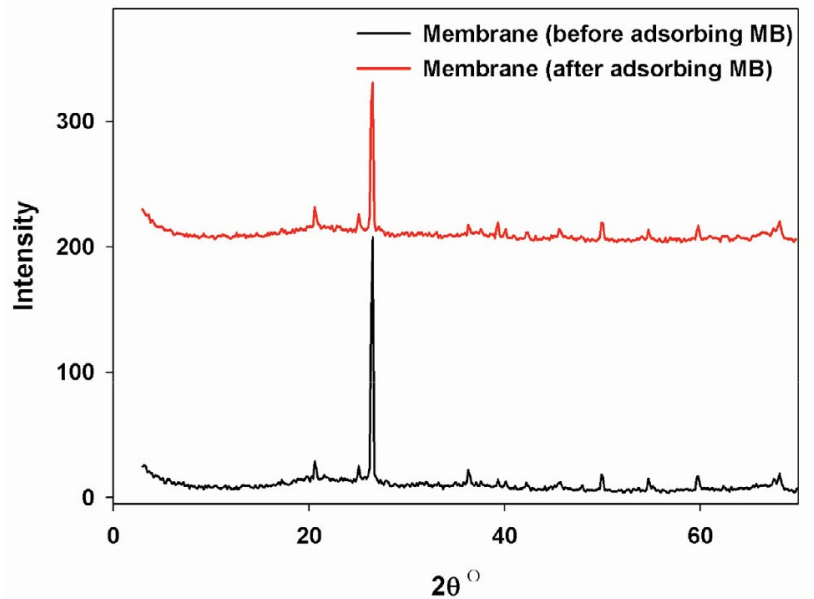

Fig. 7. XRD patterns of the ceramic membrane before and after MB adsorption.

within the clay minerals, MB ions replace alkaline earth cations. This is able to alter the peak intensity of other peaks. MB molecules were absorbed on the basal spacing of the minerals in aqueous conditions. The d-spacing is too large to be recorded by the diffractometer. It did not show quantified basal reflections of some minerals. ${ }^{6}$

\section{5. Regenerating the Ceramic Membrane}

From the previous results, the ceramic membrane loaded with $20 \%$ expanded polystyrene; sample (D) showed to be optimum in adsorbing methylene blue from water. Figure 8 illustrates the UV-Vis spectra for the aqueous solution of $\mathrm{MB}$ before and after being adsorption onto the surface of ceramic membrane related to sample (D). In addition, it shows the regeneration of the same membrane for 2 cycles. The regeneration cycles took place by immersing the dried membrane after $\mathrm{MB}$ adsorption (in the first run) for extra 24 hours to give the eluent (D-R1). This step was followed by drying the membrane then repeating a new cycle for 24 hours to produce (D-R2) eluent. The inset photos show the vials of membrane $\mathrm{D}$ in $\mathrm{MB}$ solution after 120 minutes from starting the adsorption process in addition to the resulting eluents after 24 hours and the regeneration cycles (D-R1) and (D-R2). The characteristic peaks of MB show a high energy peak at $\left(\pi-\pi^{*}\right.$ transition) in benzene. Moreover, there is a peak at low energy corresponding to ( $\mathrm{n}-\pi^{*}$ transitions) in $\mathrm{N}$ atom of $\mathrm{C}=\mathrm{N}$ bond and $\mathrm{S}$ atom on $\mathrm{S}=\mathrm{C}$ bond. ${ }^{33}$ This peak is located at $660 \mathrm{~nm}$. It may shift according to the change in the $\mathrm{pH}$ of the solution. Adsorbing MB on the ceramic surface led to bounding $\mathrm{MB}$ to the surface. Hence, $\mathrm{MB}$ vanished from the solution and these peaks did not appear. After the first regeneration cycle, it is noticed that the efficiency of the membrane did not lose its capability of adsorbing MB by providing a spectrum with slightly higher $M B$ content than the first cycle of sample (D). However, the absorption capacity of D decreased drastically in the second cycle of re-

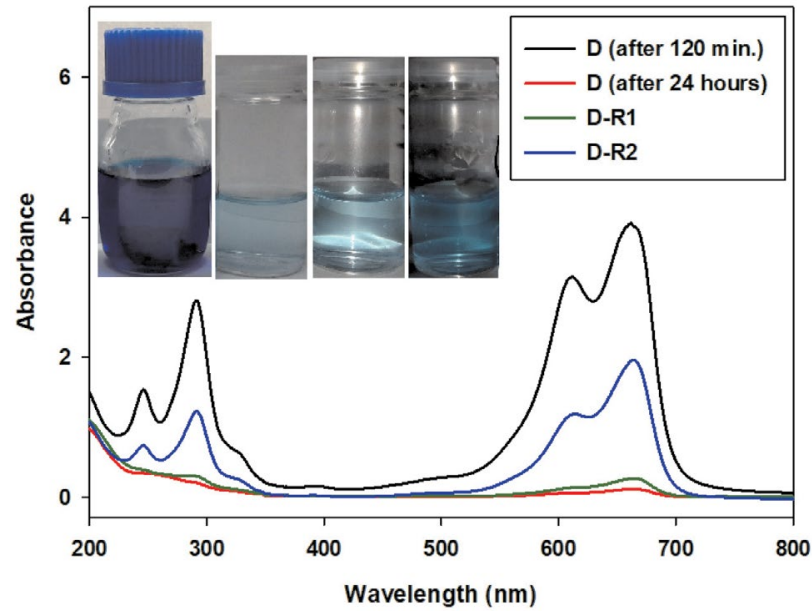

Figure 8. UV-Vis absorption spectra with inset photos for the collected eluents form $\mathrm{D}$ membrane immersed in $\mathrm{MB}$ aqueous solutions resulting from adsorption reactions after 120 min., 24 hours and regeneration cycles R1 and R2.

generation (D-R2). The eluent showed gradual increase in the blue color after regeneration cycles. This can be correlated to the growing saturation of the free sites in the surface of membrane that started to retard its efficiency towards further adsorption of methylene blue.

\section{Conclusions}

Ceramic membranes based on kaolin and expanded polystyrene have been prepared in different ratios. These membranes have been employed in removing methylene blue dye from water via adsorption. These membranes were fired at $1000{ }^{\circ} \mathrm{C}$ to degrade polystyrene leaving cavities in the clay matrix with an expanded surface area and porous structure. The morphological structure of the membranes have been developed to show the resulting changes onto the surface of the ceramic membranes after adsorbing methylene blue. The adsorption process has been tracked by an easy method which is UV-Vis spectroscopy to follow up the adsorption capacity of the prepared membranes away from adsorption isotherms and kinetic investigations. From the results, the membrane loaded with $20 \%$ polystyrene by weight; namely sample (D) membrane showed the optimum performance in adsorbing methylene blue from water. Regenerating this membrane showed a continuous adsorption capacity for the membrane that decrease due to filling the free sites of the membrane surface after using it more than once in adsorption.

\section{Acknowledgements}

The authors acknowledge the National Research Centre (NRC-Egypt) for funding this work. The authors 
also appreciate the helpful input from Dr. Hossam El-Nazer (NRC) for his assistance in performing the UV-Vis experiments.

\section{References}

1. Y. He, H. Zhang, J. Li, Y. Zhang, B. Lai, Z. Pan, Environ. Eng. Sci., 2018, 35(5), 501-511. DOI:10.1089/ees.2017.0188

2. G. Crini, E. Lichtfouse, Environ. Chem. Lett., 2019, 17(1), 145-55. DOI:10.1007/s10311-018-0785-9

3. S. Shanmuganathan, P. Loganathan, C. Kazner, M. A. H. Johir, S. Vigneswaran, Desalination, 2017, 401, 134-141. DOI:10.1016/j.desal.2016.07.048

4. S. Khamparia, D. K. Jaspal, Front. Environ. Sci. Eng., 2017, 11(1), 8. DOI:10.1007/s11783-017-0899-5

5. S. Afroze, T. K. Sen, M. Ang, H. Nishioka, Desalin. Water Treat., 2016, 57(13), 5858-5878.

DOI:10.1080/19443994.2015.1004115

6. P. T. Hang, G. W. Brindley, Clays Clay Miner., 1970, 18(4), 203-212. DOI:10.1346/CCMN.1970.0180404

7. A. Rineh, N. K. Dolla, A. R. Ball, M. Magana, J. B. Bremner, M. R. Hamblin, G. P. Tegos, M. J. Kelso, ACS Infect. Dis., 2017, 3(10), 756-766. DOI:10.1021/acsinfecdis.7b00095

8. O. Duman, S. Tunc, T. G. Polat, B. K. Bozoglan, Carbohydr. Polym., 2016, 47, 79-88. DOI:10.1016/j.carbpol.2016.03.099

9. S. Wang, L. Li, H. Wu, Z. H. Zhu, J. Colloid Interface Sci., 2005, 292(2), 336-343. DOI:10.1016/j.jcis.2005.06.014

10. A. M. Khalil, H. A. Hamed El-Nazer, M. M. Badr, A. A. Nada, J. Vinyl Addit. Technol., 2010, 16(4), 272-276. DOI:10.1002/vnl.20242

11. D. Zhang, F. Zeng, J. Mater. Sci., 2012, 47(5), 2155-2161. DOI:10.1007/s10853-011-6016-4

12. T. Xu, F. Zheng, Z. Chen, Y. Ding, Z. Liang, Y. Liu, Z. Zhengtao, H. Fong, Chem. Eng. J., 2019, 360, 280-288.

DOI:10.1016/j.cej.2018.11.233

13. M. Karbarz, A. M. Khalil, K. Wolowicz, K. Kaniewska, J. Romanski, Z. Stojek, J. Environ. Chem. Eng., 2018, 6(4), 39623970. DOI:10.1016/j.jece.2018.05.054

14. C. S. C. Chiew, H. K. Yeoh, P. Pasbakhsh, K. Krishnaiah, P. E. Poh, B. T. Tey, E. S. Chan, Appl. Clay Sci., 2016, 119, 301-310. DOI:10.1016/j.clay.2015.10.032

15. S. K. Hubadillah, M. H. D. Othman, Z. Harun, A. F. Ismail, Y. Iwamoto, S. Honda, M. A. Rahman, J. Jaafar, P. Gani, M. N. M. Sokri, Ceram. Int. 2016, 42(14), 15547-15558. DOI:10.1016/j.ceramint.2016.07.002

16. S. K. Hubadillah, M. H. D. Othman, Z. Harun, A. F. Ismail, M.
A. Rahman, J. Jaafar, S. M. Jamil, N. H. Mohtor, Mater. Lett. 2017, 191, 119-122. DOI:10.1016/j.matlet.2016.12.099

17. S. K. Hubadillah, M. H. D. Othman, T. Matsuura, A. F. Ismail, M. A. Rahman, Z. Harun, J. Jaafar, M. Nomura, Ceram. Int. 2018, 44, 4538-4560. DOI:10.1016/j.ceramint.2017.12.215

18. S. K. Hubadillah, M. H. D. Othman, A. F.Ismail, M. A. Rahman, J. Jaafar, Sep. Purif. Technol. 2019, 214, 31-39. DOI:10.1016/j.seppur.2018.04.025

19. Y. Snoussi, A. M. Khalil, B. Strzemiecka, A. Voelkel, M. M. Chehimi, Chapter 11- Surface Analysis of Clay-Polymer Nanocomposites. Clay-Polymer Nanocomposites, 2017, 363 411. Elsevier. DOI:10.1016/B978-0-323-46153-5.00011-2

20. R. Das, K. Sondhi, S. Majumdar, S. Sarkar, J. Asian Ceram. Soc. 2016, 4, 243-251. DOI:10.1016/j.jascer.2016.04.004

21. K. F. El-Nemr, A. M. Khalil, E. S. Fathy, Int. J. Polym. Anal. Charact. 2018, 23(1), 58-69. DOI:10.1080/1023666X.2017.1387447

22. R. V. Sekharan, B. T. Abraham, E. T. Thachil, Mater. Des. 2012, 40, 221-228. DOI:10.1016/j.matdes.2012.03.042

23. M. Lanzon, V. Cnudde, T. De Kock, J. Dewanckele, Constr. Build. Mater. 2015, 94, 817-825.

DOI:10.1016/j.conbuildmat.2015.07.086

24. C., Shin, G. G. Chase, D. H. Reneker, Colloids Surf. A: Physicochem. Eng. Aspects 2005, 262, 211-215.

DOI:10.1016/j.colsurfa.2005.04.034

25. T. Do, Y. G. Ko, Y. Chun, Y. K. Shin, Y. G. Kim, U. S. Choi, Polym. Eng. Sci. 2017, 57(8), 883-890.

DOI:10.1002/pen.24465

26. A. Kaya, F. Kar, Constr. Build. Mater. 2016, 105, 572-578. DOI:10.1016/j.conbuildmat.2015.12.177

27. Y. Xi, J. Li, Z. Lu, J. Jiang, Y. Niu, Constr. Build. Mater. 2019, 195, 505-514. DOI:10.1016/j.conbuildmat.2018.11.091

28. F. Uddin, Metall. Mater. Trans. A 2008, 39(12), 2804-2814. DOI:10.1007/s11661-008-9603-5

29. M. Sardy, A. Arib, K. El Abbassi, M. Gomina, (2012). New J. Glass Ceram. 2012, 2(03), 121-125.

DOI:10.4236/njgc.2012.23017

30. S. H. Kenawy, M. Hassan, R. I. Abou-Zeid, G.T. El-Bassyouni, Interceram 2017, 66(3-4), 111-116.

DOI:10.1007/BF03401207

31. N. Caponia, G. C. Collazzoa, S. L. Jahna, G. L. Dottoa, M. A. Mazuttia, E. L. Foletto, Mater. Res. (Sao Carlos, Braz.) 2017, 20, suppl.2, 14-22. DOI:10.1590/1980-5373-mr-2016-0673

32. N. M. Khalil, S.H. Kenawy, Am. Ceram. Soc. Bull. 2009, 87(7), 9201-9207.

33. S. Selvam, S., I. Sarkar, J. Pharm. Anal. 2017, 7(1), 71-75. DOI:10.1016/j.jpha.2016.07.006 


\section{Povzetek}

Onesnaževanje voda predstavlja resen okoljski problem. Med različnimi barvili, ki jih lahko najdemo v onesnaženih vodah, je tudi barvilo metilensko modro. Adsorpcija predstavlja možen učinkovit način njegovega odstranjevanja. S tem ciljem smo pripravili hibridne membrane na osnovi sljude in polimera, bolj natančno kaolina in polistirena. Membrane so bile žgane na $1000^{\circ} \mathrm{C}$, kar povzročilo razgradnjo polimera in ustvarilo praznine v nosilcu iz sljude in povečalo specifično površino ter poroznost. Membrane smo okarakterizirali z rentgensko difrakcijo in infrardečo spektroskopijo, njihovo morfologijo pa $\mathrm{z}$ vrstično elektronsko mikroskopijo. Proces adsorpcije smo zasledovali UV-Vis spektroskopijo. Maksimalno adsorpcijo smo dosegli z membrano pripravljeno z 20 \% utežnim deležem polistirena.

Except when otherwise noted, articles in this journal are published under the terms and conditions of the Creative Commons Attribution 4.0 International License 